\title{
ELEMENTOS BÁSICOS EM MECÂNICA DOS FLUIDOS: estudo quantitativo do número de Reynolds
}

Erlon Lopes PEREIRA ${ }^{1}$

Alexia Lara Souza MARTINS ${ }^{2}$

Gabriel Luz CHAVES ${ }^{3}$

Thalles Mercês CARREIRO ${ }^{4}$

Erick Eduardo Dias VIANA

${ }^{1}$ Departamento de Química. Setor de Engenharia Química. Universidade Federal de Viçosa. Campus: Viçosa-MG. CEP: 36570-900. e-mail: erlon.pereira@ufv.br/erlonlopes@gmail.com.

${ }^{2}$ Departamento de Química/ Universidade Federal de Viçosa. alexia.martins@ufv.br

${ }^{3}$ Departamento de Química/ Universidade Federal de Viçosa. gabriel.luz@ufv.br

${ }^{4}$ Departamento de Química/ Universidade Federal de Viçosa. thalles.carreiro@ufv.br

${ }^{5}$ Departamento de Química/ Universidade Federal de Viçosa. erick.viana@ufv.br

Recebido em: 16/07/2016 - Aprovado em: 16/09/2016 - Disponibilizado em: 18/12/2016

\section{RESUMO:}

O conhecimento acerca dos equipamentos básicos de fenômenos de transporte é imprescindível a um Engenheiro Químico e, além disso, ele também deve conhecer o regime de escoamento do fluido que está sendo transportado em uma linha. Em mecânica dos fluidos, avaliamos qualitativamente este escoamento pelo número de Reynolds. A prática de laboratório introduz aos alunos a um contato com a caracterização de diferentes escoamentos. Os resultados obtidos pela análise de diferentes vazões de escoamentos para o cálculo do número de Reynolds possibilitaram classifica-los como turbulento, laminar ou de transição.

Palavras-chave: Equipamentos; transporte; escoamento; Reynolds; vazões.

\section{ABSTRACT:}

The knowledge about the basic transport phenomena equipment is essential to a chemical engineer, and furthermore, he must also know the flow regime of the fluid being transported in a row. In fluid mechanics, qualitatively evaluate this flow by the Reynolds number. The laboratory practice introduces students to a contact with the characterization of different flows. The results obtained by the analysis of different flow rates of flow for calculating the Reynolds number allowed classifies them as turbulent, laminar or transition.

Keywords: Equipment; transport; flow; Reynolds; flow.

\section{INTRODUÇÃO}

Num curso de engenharia química, faz-se fundamental para o discente o contato com os equipamentos e técnicas que utilizará em sua vida profissional num distrito industrial. A disciplina Laboratório de Engenharia Química I - ENQ 271 - vem justamente para fornecer um primeiro contato do aluno com simplificações dos modelos industriais.

Um bom engenheiro químico conhece a forma de operar equipamentos do seu campo de atuação e uma boa escola de engenharia química capacita seus alunos para isso. 
A mecânica dos fluidos é a ciência que tem por objetivo o estudo do comportamento físico dos fluidos e das leis que regem este comportamento. Tal ciência tem aplicações como na ação de fluidos sobre superfícies submersas, equilíbrio de corpos flutuantes, ação de fluidos sobre veículos e construções, estudos de lubrificação, transporte de sólidos por via pneumática ou hidráulica, projeto de instalações e máquinas hidráulicas (GOMES, 2012).

De acordo com Gomes (2012), estudo do escoamento, a mecânica dos fluidos define três tipos de escoamento baseados num parâmetro adimensional, o número de Reynolds ( $R e)$, que indica se o escoamento num tubo é será laminar ou turbulento. Segundo a ABNT para $\mathrm{Re} \leq 2000$ o escoamento é laminar, $2000<\mathrm{Re} \leq 4000$ o escoamento é de transição e para $\operatorname{Re} \geq 4000$ o escoamento é turbulento.

O significado físico do $\mathrm{Re}$ é um quociente de forças entre as forças de inércia e a força de viscosidade (Equação 1). A força de inércia é dada pelo produto da velocidade com a massa específica do fluido. Já a força de viscosidade é dada pelo quociente da viscosidade dinâmica do fluido pelo diâmetro hidráulico (FUNDAÇÃO DE ENSINO E PESQUISA DE ITAJUBÁ, 2009).

$\operatorname{Re}=\frac{\rho \cdot v \cdot \mathrm{Dh}}{\mu}$

\section{Em que}

$\rho$ : massa específica do fluido $\left(\mathrm{kg} / \mathrm{m}^{3}\right)$; $\mathrm{v}$ : velocidade do fluido $(\mathrm{m} / \mathrm{s})$;

Dh: diâmetro hidráulico (m);

$\mu$ : viscosidade dinâmica do fluido $(\mathrm{kg} /(\mathrm{m} . \mathrm{s}))$.

A velocidade pode ser definida pela razão entre a vazão volumétrica $(\mathrm{Q})$ e a área de escoamento (A), como mostrado pela Equação 02. Além disso, a vazão volumétrica pode ser definida pela razão do volume pelo tempo de escoamento (Equação 03), e a vazão mássica pode ser definida pelo produto da massa específica pela vazão volumétrica (Equação 04).

$$
\begin{aligned}
\mathrm{v} & =\frac{\mathrm{Q}}{\mathrm{A}} \\
\mathrm{Q} & =\frac{\mathrm{V}}{\mathrm{t}} \\
\dot{\mathrm{m}} & =\mathrm{Q} . \rho
\end{aligned}
$$

Fazendo as devidas manipulações chegamos à Equação 05, que define o número de Reynolds ao considerarmos a área de escoamento como $\pi \cdot \mathrm{Dh}^{2} / 4$.

$$
\operatorname{Re}=\frac{4 \cdot \rho \cdot V}{\pi \cdot D h \cdot \mu \cdot t}
$$

O presente trabalho teve como objetivo apresentar uma revisão sobre dispositivos básicos na mecânica dos fluidos, bem como desenvolver um experimento para aplicação dos conceitos descritos buscando contribuir com o processo de ensino-aprendizagem dos cursos que necessitam desse embasamento profissional. 


\section{MATERIAIS E MÉTODOS}

\subsection{Pesquisa teórica}

A pesquisa de fundamentação teórica foi realizada com base nos trabalhos publicados por Gomes (2012); Fundação de Ensino e Pesquisa de Itajubá (2009); Cremasco (2011); Brasil (2013); Ortega (2008); Moura Júnior \& Melo (2014); Telles (2005); Smith, Van Ness\&Abbott (2007); White (2011); Amorim (2010);Figueiredo Neto \& Cardoso (1999); Ferraz (2009); Marinho (2010); Bojorge (2014) e Andrade \& Horta (2005).

\subsection{Aparato experimental}

Água da rede.

Tomada 220V.

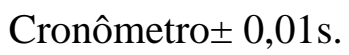

$\checkmark \quad$ Régua milimetrada $\pm 0,5 \mathrm{~mm}$.

$\checkmark \quad$ Termômetro $\pm 0,5^{\circ} \mathrm{C}$.

Software Engineering Equation Solver
Bancada hidráulica volumétrica fabricada em acrílico modelo H1D (Figura 1).

A bancada (Figura 1) consiste em uma bancada constituída de um reservatório de fluido principal com $160 \mathrm{~L}$ de capacidade, um reservatório interno (tanque volumétrico) de 35 L de capacidade, uma bomba elétricasubmersa com capacidade de 0 a 60 litros por minuto a $1,5 \mathrm{~m}$ de altura um sistema de medição de vazão e uma superfície de trabalho sobre a bancada principal, dotada de pontos para a montagem de acessórios para o desenvolvimento de diversos experimentos em mecânica dos fluidos e hidráulica, sem a necessidade de reabastecimento de fluido. A bancada também conta com um indicador de nível do tanque volumétrico em escala em litros precisamente calibrado. Possui dimensões de $1200 \mathrm{~mm}$ x $760 \mathrm{~mm}$ x 1100 $\mathrm{mm}$.

(EES).

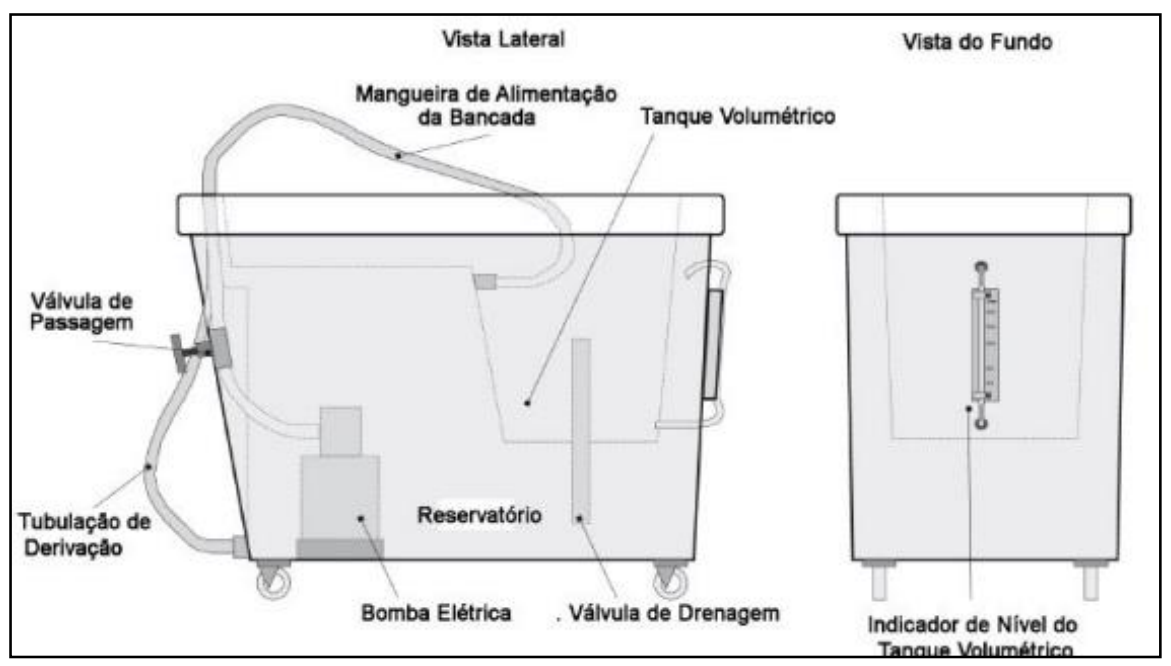

Figura 1 - Ilustração da bancada volumétrica H1D. 


\subsection{Procedimento experimental}

Inicialmente coletou-se as incertezas de cada instrumento utilizado (item 2.2), abriu-se a conexão de água e conectou-se a tomada que alimentava o motor da bomba encontrada na bancada, a rede elétrica.

A temperatura da água que alimenta a bancada foi quantificada com o termômetro e utilizada na determinação da sua massa específica de acordo com Perry (1997)

No experimento foram realizados seis ensaios com três repetições cada. Cada ensaio foi caracterizado por um valor de vazão volumétrica $(\mathrm{Q})$, modificada pelo ajuste da válvula de passagem de água. A quantificação da vazão de cada ensaio foi realizada quando o escoamento do fluido na bancada mostrouse uniforme. Nesse momento, fechou-se o tanque volumétrico com a válvula de drenagem/estanqueador e o tempo necessário para encher um volume predefinido de 15

litros foi marcado. Para tal utilizou-se dois cronômetros que foram iniciados ao mesmo tempo. Esses dados foram utilizados para determinação da Q. Após o termino do ensaio a abertura válvula foi realizada para modificação do valor de $\mathrm{Q}$ e o procedimento foi repetido.

\subsection{Cálculo da propagação de incertezas.}

Para os cálculos da propagação de incertezas foram utilizadas as definições das equações 06 e 07.

$$
\begin{aligned}
& \mathrm{K}=\mathrm{f}\left(\mathrm{X}_{1}, \mathrm{X}_{2}, \ldots, \mathrm{X}_{\mathrm{N}}\right) \\
& \mathrm{w}=\sqrt{\sum_{\mathrm{i}=1}^{\mathrm{N}}\left(\frac{\partial \mathrm{K}}{\partial \mathrm{X}_{\mathrm{i}}}\right)^{2} \mathrm{w}_{\mathrm{i}}{ }^{2}}
\end{aligned}
$$

Utilizou-se, portanto, o software EES para aplicar as definições acima e calcular a incerteza propagada das medidas para os diversos resultados objetivados pelo experimento, aplicando os valores previamente apresentados das incertezas de cada instrumento, bem como os valores apresentados que serão apresentados posteriormente como resultados experimentais.

\section{RESULTADOS E DISCUSSÃO}

\subsection{Revisão Teórica}

\subsubsection{Bombas}

Bombas são dispositivos fluidomecânicos que fornecem energia mecânica a um fluido incompressível líquido para transportá-lo de um lugar a outro. Essas máquinas geratrizes recebem energia de uma fonte qualquer e cedem parte dessa energia ao fluido na forma de energia de pressão, cinética ou ambas. São empregadas em diversas situações, cabendo ressaltar: abastecimento de água; sistemas de esgoto e tratamento de resíduo; sistemas de irrigação para fins agrícolas; nas indústrias química, petroquímica, alcoolquímica, farmacêutica, de alimentos, entre outras indústrias (CREMASCO, 2011).

A classificação das bombas é dada a partir do modo que se obtém energia, além de 
como essa energia é cedida ao fluido. De acordo com Brasil (2013), as bombas dinâmicas ou turbobombas fornecem energia ao líquido por meio de um impulsor ou rotor, de modo a aumentar a sua energia cinética que, por sua vez, é transformada em energia de pressão. As bombas centrífugas radiais desenvolvem altas pressões sendo, portanto, adequadas para baixas vazões. Já nas bombas de fluxo axial a energia transferida para o líquido é por meio da ação de forças de arraste, esse tipo de bomba opera a altas vazões e baixas pressões. Por fim, nas bombas centrífugas mistas a energia cinética é transferida ao líquido tanto por meio de forças centrífugas quanto por forças de arraste.

Segundo Ortega (2008) a utilização de bombas centrífugas é vantajosa porque a construção é simples, de baixo custo, o fluido é descarregado a uma pressão uniforme, a linha de recalque pode ser estrangulada ou completamente fechada sem danificar a bomba, permite bombear líquidos com sólidos, podem ser acopladas diretamente a motores, não há válvulas envolvidas na operação de bombeamento e menores custos de manutenção que outros tipos de bombas. Sendo as desvantagens a não possibilidade de utilização em altas pressões, o máximo rendimento das bombas ocorre num intervalo limitado de condições, não bombeiam eficientemente líquidos muito viscosos, as bombas estão sujeitas à incorporação de ar e precisam ser escorvadas. Já nas bombas de deslocamento não há transformação de energia cinética em energia de pressão, uma vez que, nessas bombas a energia fornecida ao líquido advém da variação do volume do fluido na própria bomba.

Todas as bombas possuem condições que aperfeiçoam sua utilização. Tais condições variam com o tipo de fluido, a faixa de pressão e vazão volumétrica. Sendo que, das condições ideais tem-se a altura de sucção disponível ou saldo positivo de carga de sucção (NPSH), que representa a condição ideal abaixo da qual causará cavitação, fenômeno relacionado à ebulição do líquido sob determinadas condições de pressão de vácuo e temperatura, formando bolhas que causam perda de rendimento da bomba, além de estraga-la (CREMASCO, 2011).

Segundo Moura Júnior \& Melo (2014) é possível o acoplamento de bombas a sistemas em séries ou em paralelo. Bombas conectadas em série visam fornecer alturas maiores, operando a uma mesma vazão, sendo, portanto, a altura fornecida igual à soma das alturas de cada bomba. Em contrapartida, o acoplamento em paralelo permite a operação a vazões diferentes, as bombas ajustam a vazão de modo a manter constante a diferença de pressão.

O Quadro 01 apresenta os diversos tipos de bombas. 
Quadro 01. Tipos comuns de bombas.

\begin{tabular}{|c|c|c|c|}
\hline $\begin{array}{l}\text { Tipo de } \\
\text { bomba }\end{array}$ & Aplicações usuais & Modelos comerciais & $\begin{array}{c}\text { Características } \\
\text { principais }\end{array}$ \\
\hline $\begin{array}{l}\text { Bomba } \\
\text { Centrífuga }\end{array}$ & $\begin{array}{l}\text { Normalmente é usada } \\
\text { para bombeamento } \\
\text { deprodutos químicos em } \\
\text { geral (soda cáustica, } \\
\text { sulfatos,cloretos, } \\
\text { hipoclorito de sódio,leite } \\
\text { de cal, etc.) e soluções } \\
\text { industriais corrosivas } \\
\text { (banhosgalvânicos, } \\
\text { efluentes ácidos } \\
\text { ealcalinos, etc.). } \\
\text { (GRABE, 2016). }\end{array}$ & $\begin{array}{l}\substack{\text { Bocal de } \\
\text { sucçac }} \\
\text { Fonte: Portal da Indústria (2009). }\end{array}$ & $\begin{array}{l}\text { O rotor centrífugo é } \\
\text { responsávelpelo } \\
\text { deslocamento de } \\
\text { líquidopara a tubulação } \\
\text { de descargae o } \\
\text { contrarrotortem a } \\
\text { função de coletar } \\
\text { olíquido que } \\
\text { normalmente } \\
\text { vazariapelo orifício de } \\
\text { passagem doeixo da } \\
\text { bomba, bombeando-o } \\
\text { novamente para dentro } \\
\text { da carcaça da mesma. } \\
\text { (GRABE, 2016). }\end{array}$ \\
\hline $\begin{array}{l}\text { Bomba } \\
\text { submersa }\end{array}$ & $\begin{array}{lr}\begin{array}{lr}\text { Drenar água limpa ou } \\
\text { turva em } \\
\text { viscinas, } \\
\text { vazamentos }\end{array} \\
\text { lavanderias ou } & \text { áreas } \\
\text { inundadas. } & \text { (KSB } \\
\text { BRASIL, 2016) } & \end{array}$ & $\begin{array}{l}\text { Fonte: Portal da Indústria(2009). } \\
\end{array}$ & $\begin{array}{l}\text { Os corpos da bomba } \\
\text { radial são unidos por } \\
\text { meio de tirantes e os da } \\
\text { bomba semi-axial por } \\
\text { meio de prisioneiros e } \\
\text { porcas. O corpo de } \\
\text { sucção entre a bomba e } \\
\text { o motor tem um crivo } \\
\text { para proteger a bomba } \\
\text { contra impurezas } \\
\text { contidas no líquido } \\
\text { bombeado. (KSB } \\
\text { BRASIL, 2016) }\end{array}$ \\
\hline $\begin{array}{l}\text { Bomba } \\
\text { autoaspirante }\end{array}$ & $\begin{array}{l}\text { Transferência de grandes } \\
\text { quantidades de água } \\
\text { como em poços ou lagos } \\
\text { de até seis metros de } \\
\text { profundidade. (LEROY } \\
\text { MERLIN, 2014). }\end{array}$ & $\begin{array}{l}\text { Fonte: Portal da Indústria (2009). } \\
\text { (1)- }\end{array}$ & $\begin{array}{l}\text { A bomba autoaspirante } \\
\text { se tem a vantagem de } \\
\text { não precisar de ser } \\
\text { previamente enchida } \\
\text { com o líquido a ser } \\
\text { bombeado. Ela expulsa } \\
\text { por si só o ar entre o } \\
\text { corpo da bomba e tubo } \\
\text { de aspiração. } \\
\text { (BRASIL, 2010) }\end{array}$ \\
\hline $\begin{array}{l}\text { Bomba } \\
\text { periférica }\end{array}$ & $\begin{array}{l}\text { Sucção e recalque de } \\
\text { água limpa e livre de } \\
\text { sólidos em pequenas } \\
\text { irrigações, abastecimento } \\
\text { de residências e } \\
\text { transferência de água de } \\
\text { cisternas. (DANCOR, } \\
\text { 2016). }\end{array}$ & Fonte: Leo Group (2016). & $\begin{array}{l}\text { Apresenta baixo custo, } \\
\text { bombeia água com } \\
\text { maior pressão que } \\
\text { bombas centrífugas. É } \\
\text { intermediária entre as } \\
\text { centrífugas e as de } \\
\text { deslocamento. } \\
\text { (LEROY MERLIN, } \\
\text { 2014). }\end{array}$ \\
\hline
\end{tabular}




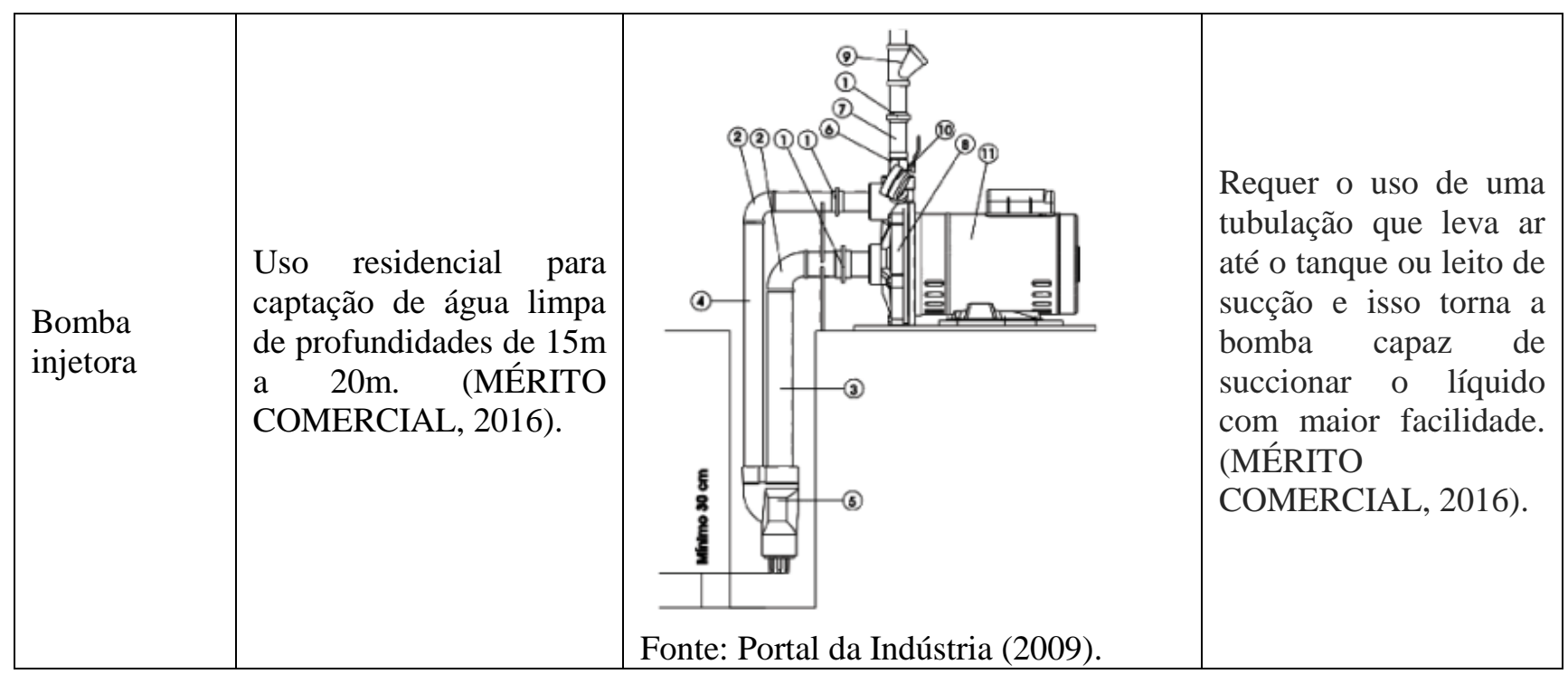

\subsubsection{Válvulas}

As válvulas estabelecem, controlam e interrompem o fluxo em uma tubulação, sendo consideradas os acessórios mais importantes existentes nas tubulações. As instalações devem conter sempre o menor número possível de válvulas, compatível com o funcionamento da mesma, porque além de serem peças caras, há possibilidade de vazamentos e introduzem perdas de carga, às vezes de grande valor. Sendo assim, a localização das válvulas deve estudada com cuidado, para que a manobra e a manutenção das mesmas sejam fáceis (ANDRADE; HORTA, 2005).

Segundo White (2011) as perdas de carga associadas às válvulas e a qualquer outro acessório são conhecidas como perdas de carga localizadas, perdas dadas em função da separação do escoamento e calculadas pela Equação 08.

$$
\mathrm{h}_{\mathrm{l}}=\mathrm{f} \cdot \frac{\mathrm{L}_{\mathrm{e}}}{\mathrm{Dh}} \cdot \frac{\mathrm{v}^{2}}{2 \cdot \mathrm{g}}
$$

Em que

$\mathrm{h}_{1}$ : perda de carga localizada (mca)

$\mathrm{f}$ : fator de atrito (adimensional);

$\mathrm{L}_{\mathrm{e}}$ : comprimento equivalente do tubo reto (m);

Dh: diâmetro hidráulico (m);

$\mathrm{V}$ : velocidade do fluido $(\mathrm{m} / \mathrm{s})$;

g: aceleração da gravidade $\left(\mathrm{m} / \mathrm{s}^{2}\right)$.

De acordo com Amorim (2010), os principais tipos de válvula são as de bloqueio, as de regulagem, as que permitem escoamento somente em um sentido e as de controle de pressão. Entre os sistemas usados para a operação de válvulas podemos destacar os de operação manual, motorizada e automática.

As válvulas de bloqueio são destinadas a estabelecer ou interromper o fluxo, funcionando completamente abertas ou fechadas. Dentre elas tem-se a válvula gaveta, que quando totalmente abertas há pouca perda de carga, quando parcialmente aberta há perda de carga elevada, cavitação e corrosão; há 
também as válvulas macho, que são utilizadas em bloqueio de gases e líquidos, inclusive com sólidos em suspensão, podendo ser encontradas como válvula esfera e válvula de três vias (FIGUEIREDO NETO e CARDOSO, 1999).

Segundo Figueiredo Neto \& Cardoso (1999) as válvulas de regulagem destinam-se a controlar o escoamento, operando em qualquer posição de fechamento parcial. Dentre elas tem-se a válvula globo que causa em qualquer posição de fechamento fortes perdas de carga, uma vez que há mudanças de direção e turbilhonamento do fluido dentro da válvula; as válvulas em Y possuem a haste disposta de modo que a trajetória da corrente de líquido fique quase retilínea, minimizando a perda de carga, sendo indicadas para uso com produtos corrosivos; as válvulas borboletas são de regulagem que também podem ser utilizadas como de bloqueio, seu emprego tem aumentado por serem leves, baratas, facilmente adaptáveis, provocarem pequena perda de carga e por poderem ser usadas com líquidos de alta e baixa viscosidade.

As válvulas que permitem o escoamento em um só sentido incluem as válvulas de pé, que são instaladas na extremidade da linha mergulhada no reservatório de sucção, impedindo o esvaziamento do tubo de sucção; e incluem também as válvulas de retenção que operam automaticamente pela diferença de pressões, costumando provocar elevada perda de carga (ORTEGA, 2008).

As válvulas de controle de pressão incluem as válvulas de segurança e alívio, que se abrem automaticamente quando a pressão ultrapassa um determinado valor e fecham-se quando a pressão cair abaixo do valor de abertura, denominadas de "segurança" quando destinadas a fluidos compressíveis e "de alívio" quando trabalham com fluidos incompressíveis; e incluem também as válvulas redutoras de pressão, que regulam a pressão dentro de limites pré-estabelecidos, são muito utilizadas nas instalações de vapor e ar comprimido, nas redes de abastecimento de água nas cidades e nas instalações de água em prédios altos (FIGUEIREDO NETO e CARDOSO, 1999).

O Quadro 02 seguinte resume os principais tipos de válvulas e suas principais aplicações. 
Quadro 02. Tipos mais comuns de válvulas

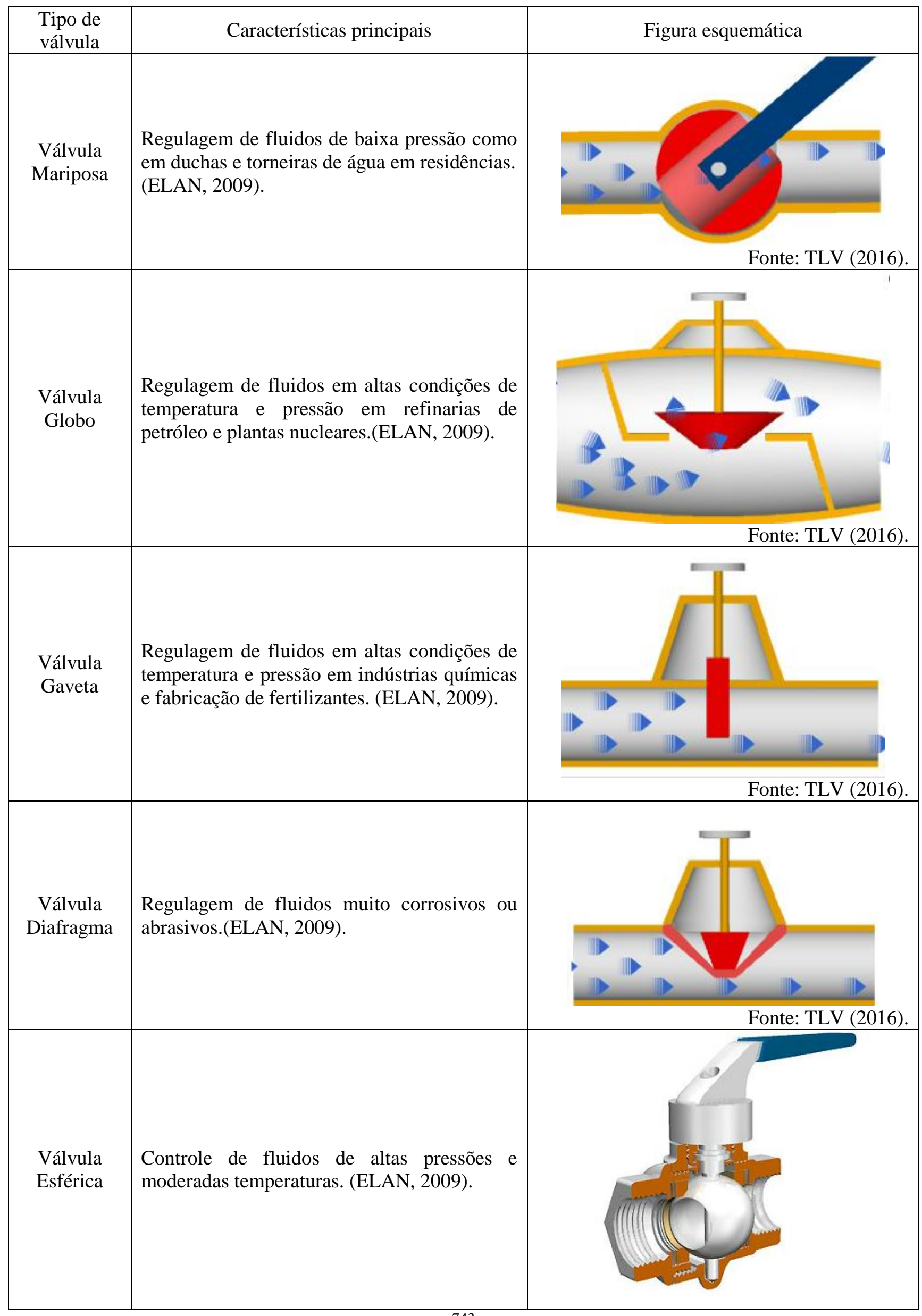




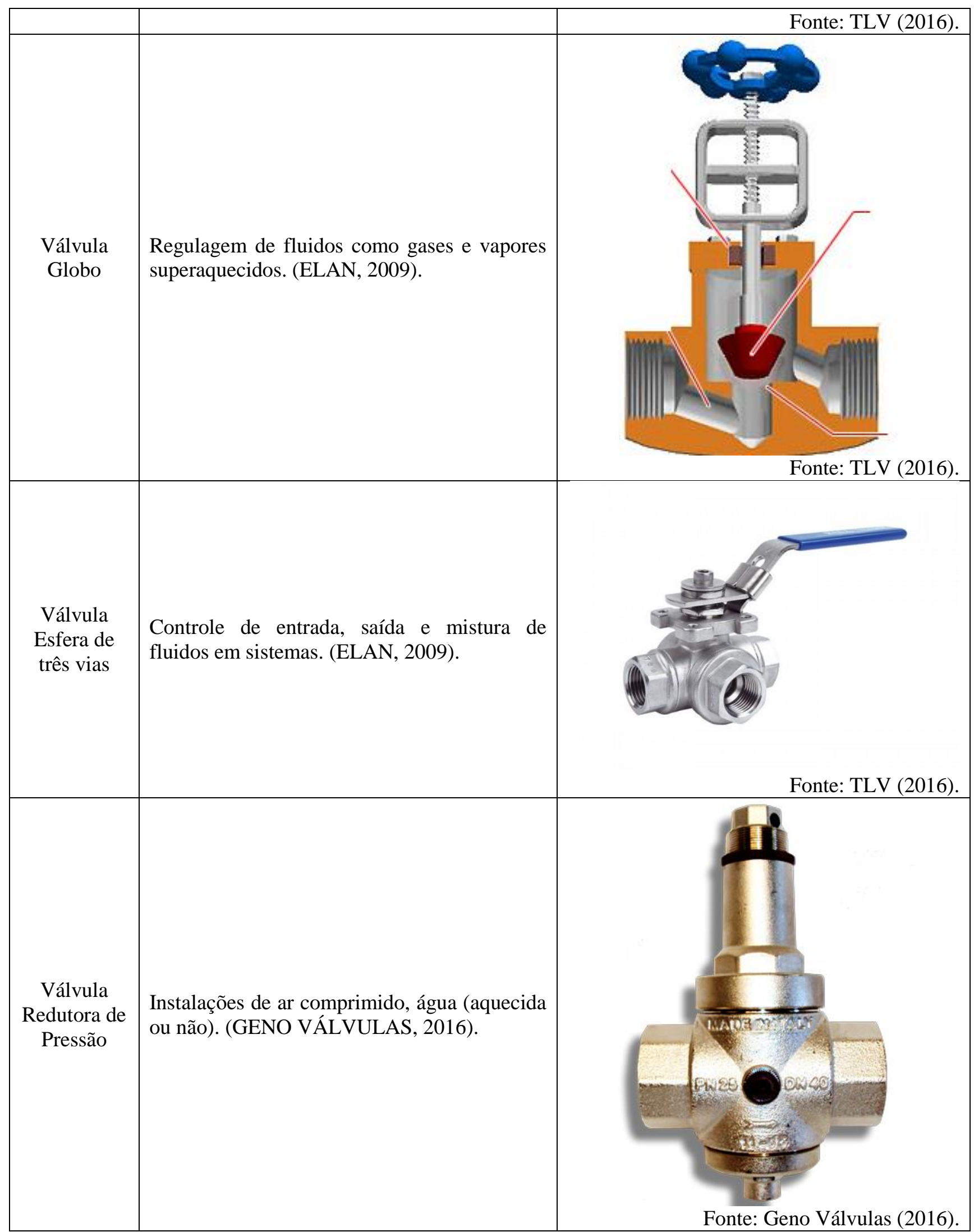




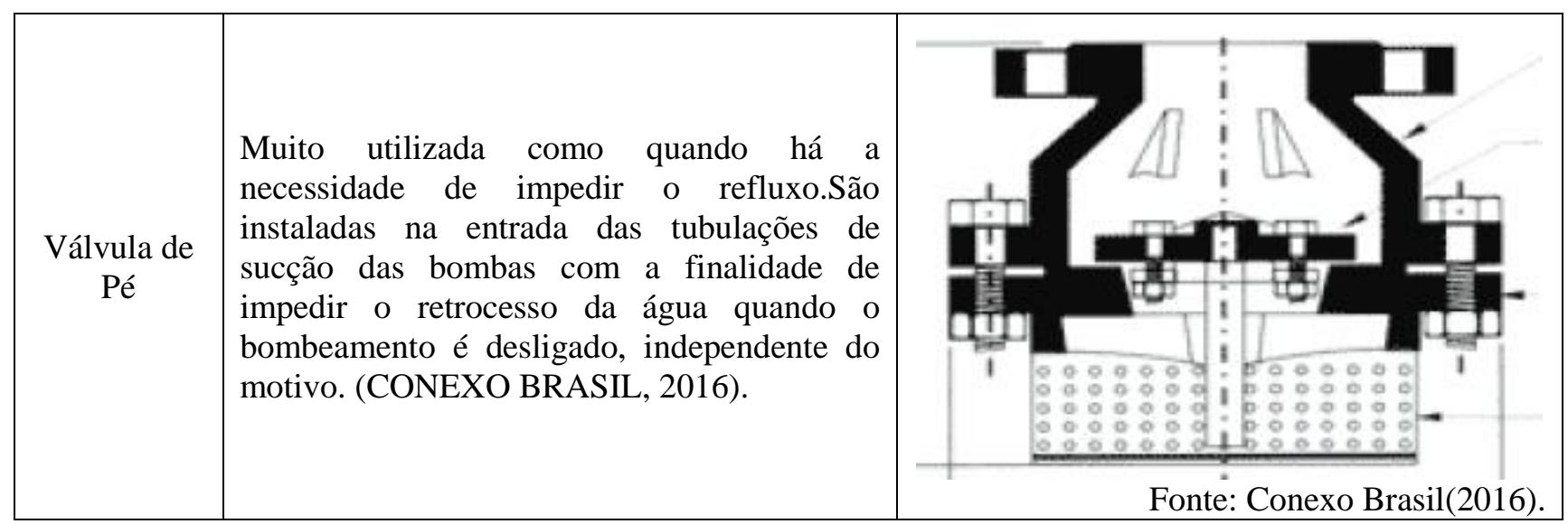

\subsubsection{Tubulações}

Os tubos são dutos fechados destinados ao transporte de fluidos sendo geralmente de seção circular. Com exceção dos tubos que transportam fluidos alimentícios que são de aço inoxidável, as tubulações destinadas a outros fins comumente são de ferro, aço-carbono, bronze ou cobre. Geralmente os tubos são definidos pelo diâmetro externo e a espessura da parede, sendo de $1,5 \mathrm{~mm}$ para todos os diâmetros disponíveis no mercado, exceto o tubo de 4" (ANDRADE \& HORTA, 2005).

De acordo com White (2011) para as tubulações chamamos a perda de carga de distribuída, representada na equação 09, a nova variável L representa o comprimento da tubulação em questão.

$\mathrm{h}_{\mathrm{d}}=\mathrm{f} \cdot \frac{\mathrm{L}}{\mathrm{Dh}} \cdot \frac{\mathrm{v}^{2}}{2}$

\section{Em que}

$\mathrm{h}_{\mathrm{d}}$ : perda de carga distribuída (mca);

f: fator de atrito (adimensional);

$\mathrm{L}$ : comprimento tubo reto $(\mathrm{m})$;

Dh: diâmetro hidráulico (m);

$\mathrm{v}$ : velocidade do fluido $(\mathrm{m} / \mathrm{s})$;

g: aceleração da gravidade $\left(\mathrm{m} / \mathrm{s}^{2}\right)$.

Segundo Telles (2005) a classificação dos dutos fechados pode variar de acordo com uma série de aspectos, tais como o setor em que serão empregados e o material que transportarão (Figura 2). 
Figura 2 -Possíveis destinos das tubulações industriais.Fonte: Telles, 2005.

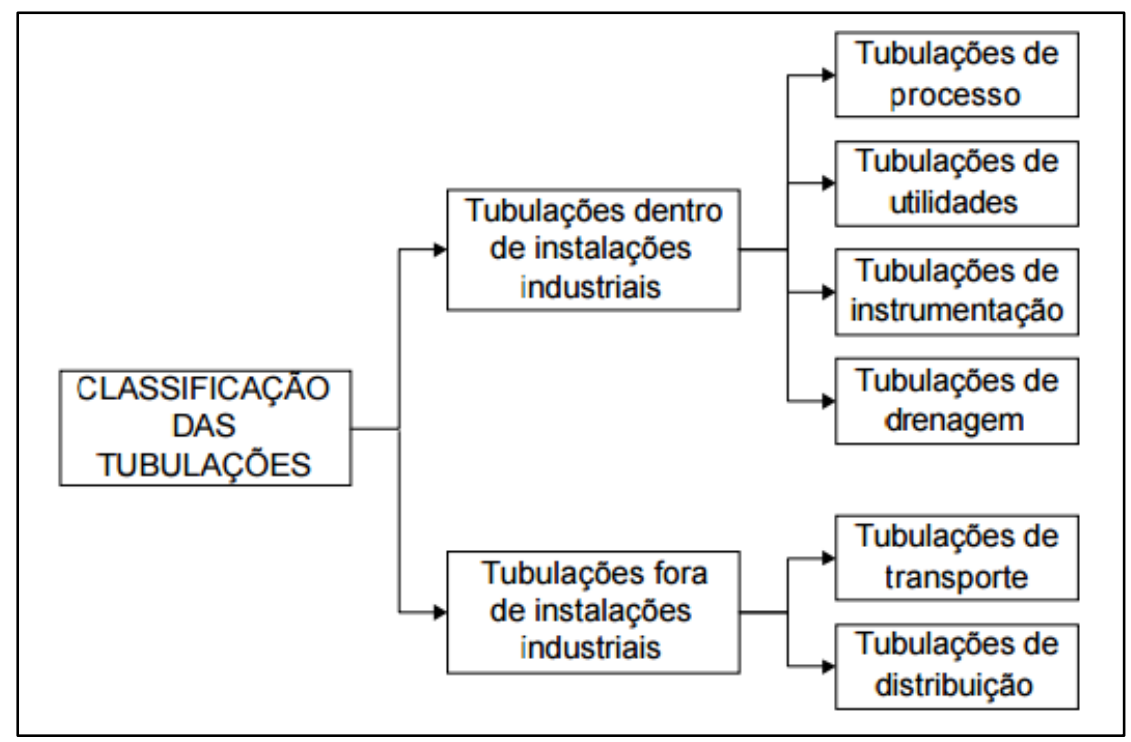

O Quadro 03 resume os principais tipos de tubulações e suas aplicações.

Quadro 03. Tipos de tubulações

\begin{tabular}{|c|c|c|}
\hline $\begin{array}{c}\text { Tipos mais } \\
\text { comuns }\end{array}$ & \multicolumn{1}{c|}{ Aplicações frequentes } \\
\hline $\begin{array}{c}\text { Tubos de } \\
\text { aço- } \\
\text { carbono }\end{array}$ & $\begin{array}{l}\text { Transporte de água doce, óleo e outros } \\
\text { materiais pouco corrosivos em temperaturas } \\
\text { de até } 370^{\circ} \mathrm{C} . \text { (CONSTRUFÁCIL, 2016). }\end{array}$ \\
\hline $\begin{array}{c}\text { Tubos de } \\
\text { PVC }\end{array}$ & $\begin{array}{l}\text { Transporte de água limpa à temperatura } \\
\text { ambiente. (CONSTRUFÁCIL, 2016). }\end{array}$ \\
\hline
\end{tabular}




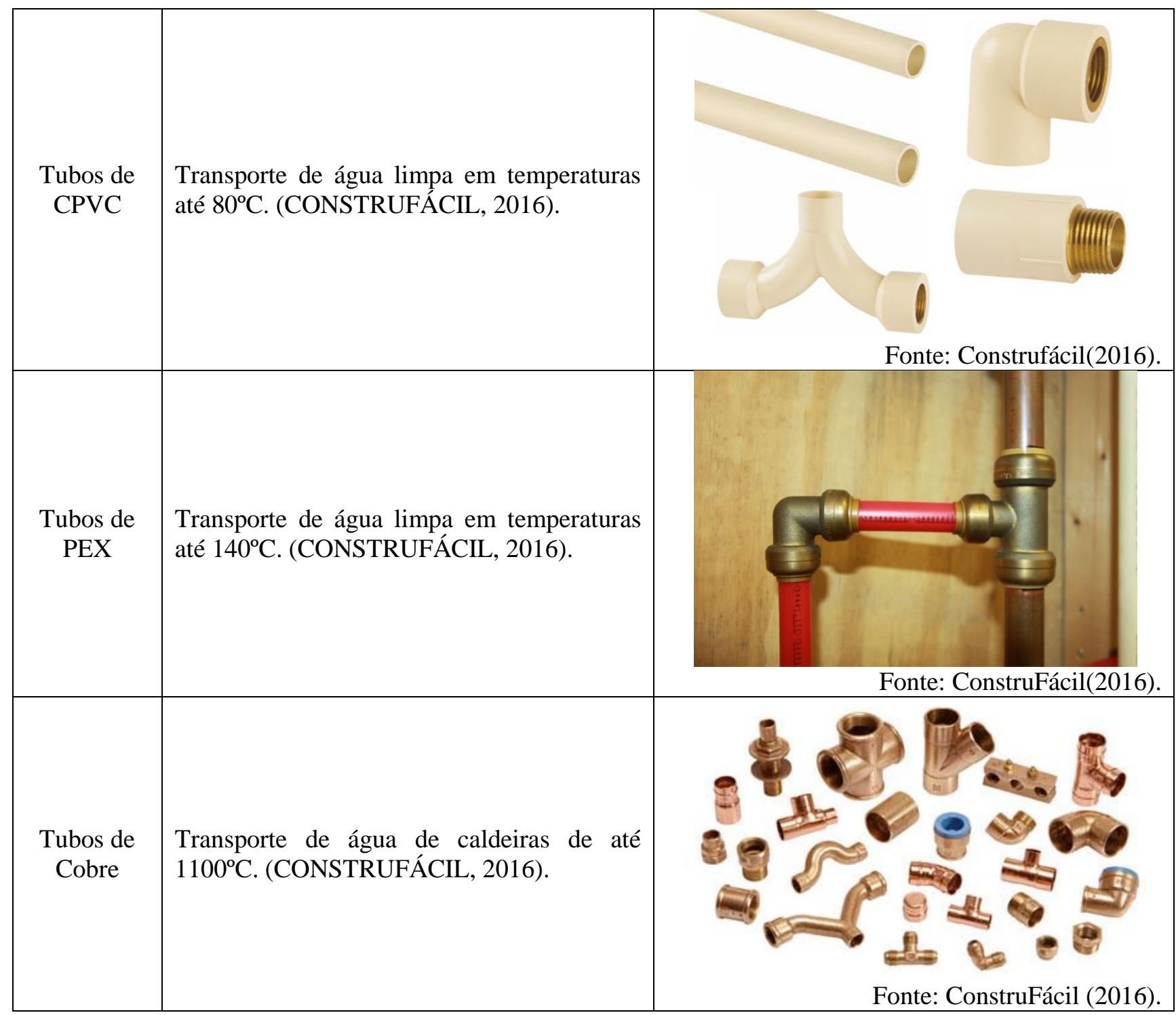

\subsubsection{Acessórios}

Para Ferraz (2009), acessórios compõem os sistemas de tubulações para conectar diretamente tubos ou partes de tubulações, regulando fluxos e adaptando diferentes tamanhos e formas, ou para permitir o controle e análise dos processos desenvolvidos. Desencadeiam perda de carga localizada, designada pela Equação 08.

Em relação ao sistema de ligação empregado, os acessórios de tubulação podem ser classificados em acessórios para solda de topo, para solda de encaixe, rosqueados, flangeados, para ligações de compressão e de ponta e bolsa (ANDRADE \& HORTA, 2005). A Figura de 03 apresenta a grande variedade de acessórios existentes.

Existem também acessórios que permitem o controle e análise do processo desenvolvido, como medidor de temperatura, medidor de pressão, indicador de nível e purgadores. 
Figura 3 - Acessórios. Fonte: ANDRADE \& HORTA, 2005.

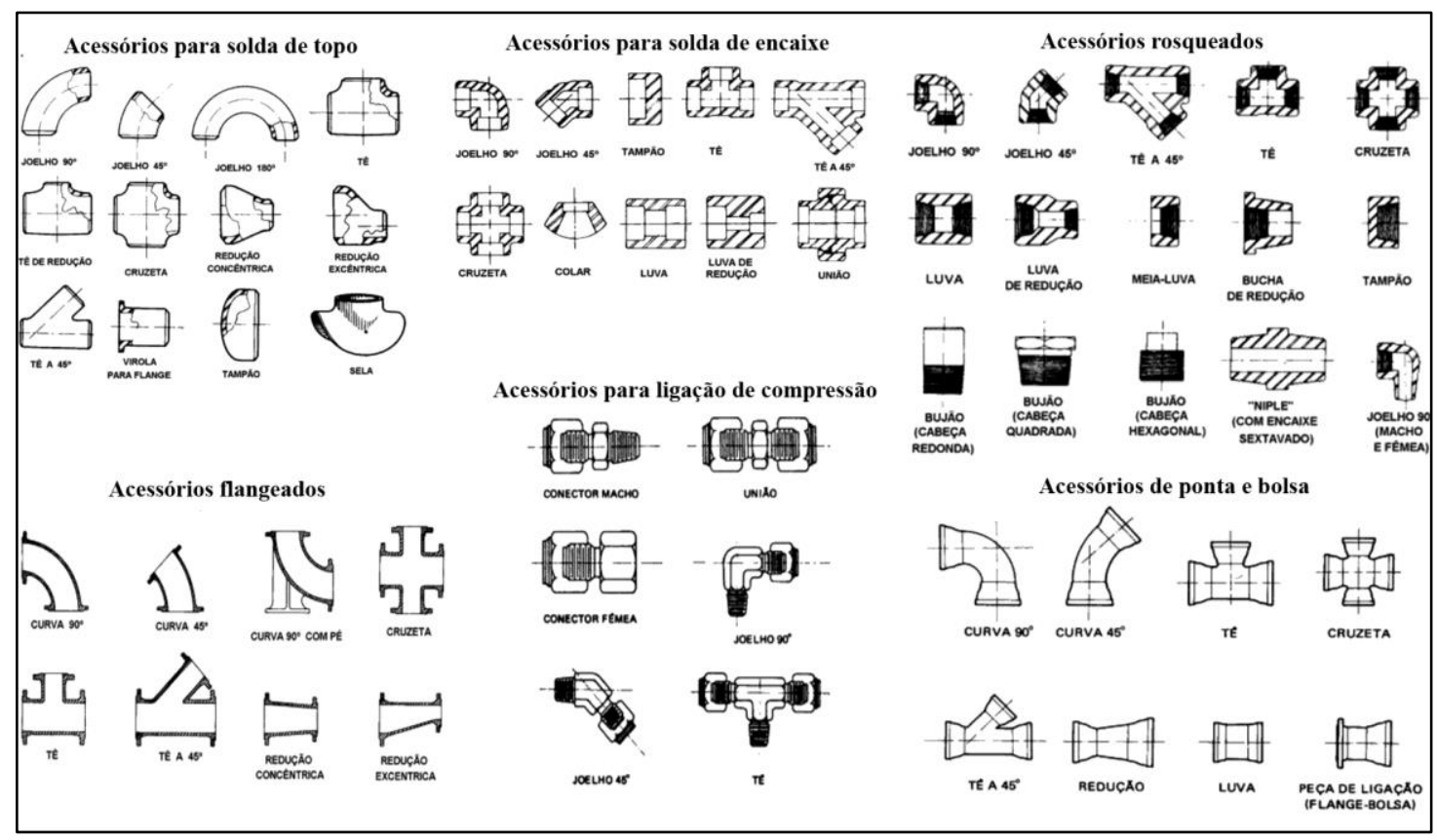

Dentre os medidores de temperatura o termômetro bi-metálico é o mais comumente utilizado quando se deseja uma medida simples com um mecanismo mecânico de fácil compreensão, a junta metálica curva-se aproximando do corpo de maior temperatura. Há ainda os termômetros por resistência elétrica, que é composto por condutores ou semicondutores que, em contato com o objeto, variam a sua resistência, sendo a leitura feita de forma indireta (equação de linearização) ou direta (leitor acoplado ao aparelho). Os termopares são os principais termômetros utilizados na indústria, apesar de funcionarem em função de gradientes de temperatura e não da temperatura, como outros medidores. Por fim, há também termômetros por radiação, que oferecem a vantagem de não necessitarem de contato para aferir a temperatura, sendo mais caros devido a essa sensibilidade (MARINHO 2010).

Medidores de pressão são essenciais para garantir o monitoramento e controle da pressão ideal de cada processo. Quando a pressão utilizada é maior que a do ambiente utiliza-se um manômetro. Quanto à sua calibração, os autores Smith, Van Ness\&Abbott (2007) definem o padrão para a medição como o valor lido em um manômetro a contrapeso, no qual a força conhecida é contrabalanceada pela pressão exercida por um fluido em determinada área. Já para pressões menores que a ambiente, o ideal é o uso de vacuômetros.

De acordo com Bojorge (2014) os medidores de nível são utilizados para conhecer o nível do fluido e determinar, de maneira indireta, seu fluxo, podendo ser analógicos, digitais ou um simples medidor de 
comprimento. Tal acessório é de fundamental importância para evitar danos à estrutura por falta ou excesso de fluido, que podem interromper $\mathrm{o}$ processo gerando perdas significativas e até acidentes.

Os purgadores são utilizados para remover ar ou condensado, evitando a perda de vapor. $\mathrm{O}$ condensado interfere em processos de transferência de calor reduzindo a área de troca térmica, logo é interessante sua remoção. Esse acessório é um dispositivo automático, sendo instalado o mais próximo possível do ponto de drenagem, coletando o condensado de maneira intermitente quando necessário (Telles 2005).

O Quadro 04 resume outros principais tipos de acessórios e suas aplicações.

Quadro 04. Tipos comuns de acessórios

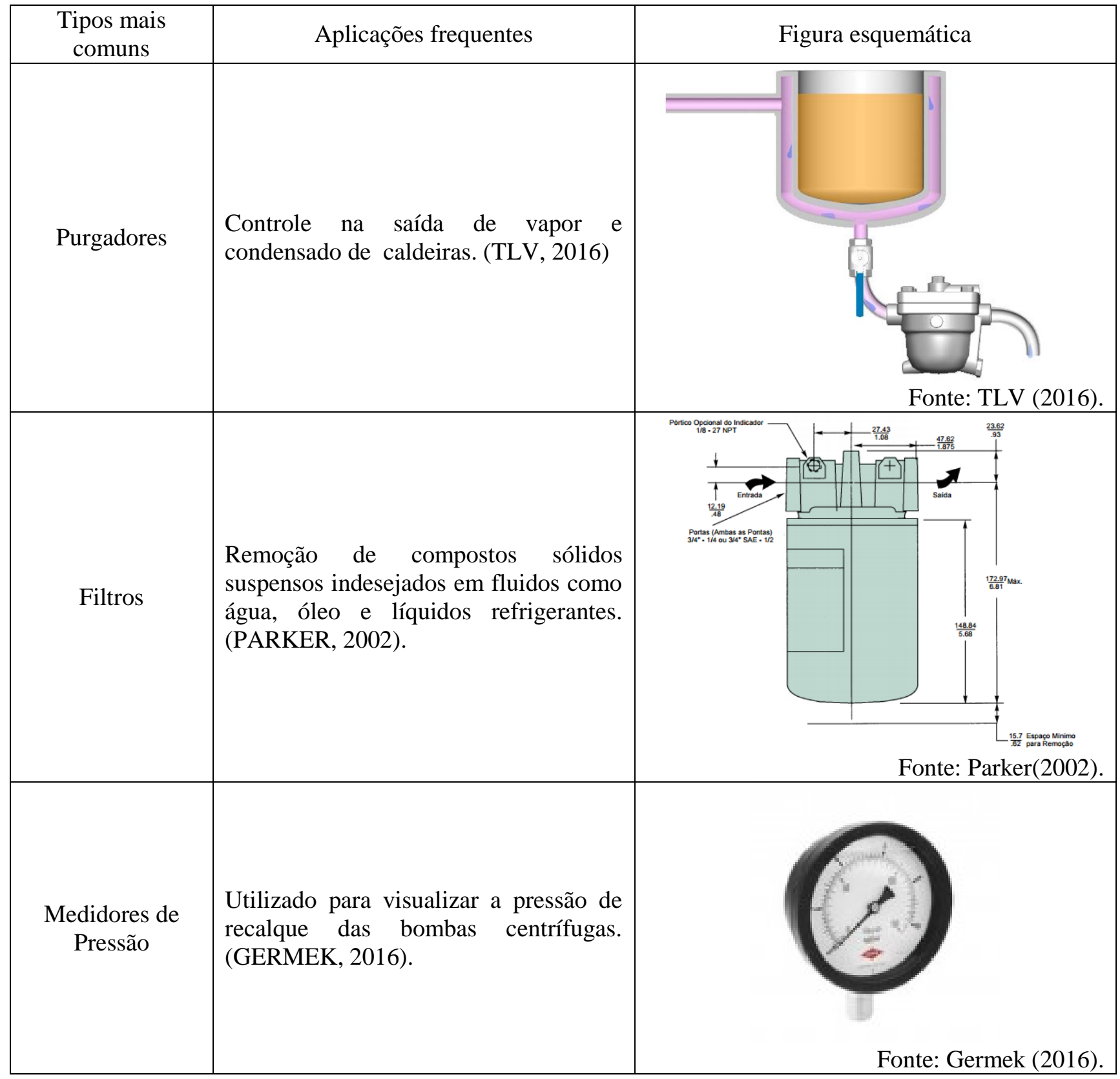




\begin{tabular}{|c|l|l|l|}
\hline $\begin{array}{c}\text { Medidores de } \\
\text { Temperatura } \\
\text { (ECIL, 2016). }\end{array}$ & $\begin{array}{l}\text { Indústria alimentícia e farmacêutica. } \\
\text { Indicadores de } \\
\text { nível }\end{array}$ & $\begin{array}{l}\text { Medição contínua e visual do nível de } \\
\text { fluido em tanques de leite. (WIKA, } \\
\text { 2016). }\end{array}$ \\
\hline
\end{tabular}

\subsection{Resultados Experimentais}

O experimento realizado foi iniciado com as devidas medições, obtendo, para os três primeiros ensaios, uma temperatura de $25,1^{\circ} \mathrm{C}$ e para os três ensaios seguintes, uma temperatura de $26,0^{\circ} \mathrm{C}$. Além disso, mediu-se também o diâmetro hidráulico da tubulação de escoamento da água e obteve-se o valor de $2,6 \mathrm{~cm}$.

De acordo com Perry (1997), a massa específica da água a $25,1^{\circ} \mathrm{C}$ é $997,019 \mathrm{~kg} \mathrm{~m}^{-3}$ e a viscosidade dinâmica é $0,8884 \times 10^{-3} \mathrm{~Pa} \mathrm{~s}$, já a $26,0^{\circ} \mathrm{C}$, obtém-se uma massa específica de $996,783 \mathrm{~kg} \mathrm{~m}^{-3}$ e uma viscosidade dinâmica de $0,871 \times 10^{-3} \mathrm{~Pa}$ s.

Em seguida, foram realizadas as medições para cada ensaio para os cálculos de objetivo do experimento. Os resultados obtidos nos seis ensaios estão apresentados na Tabela 01.

Utilizando as equações 03, 04 e 05, foram calculadas as vazões volumétrica, mássica e Re apresentados na Tabela 02 para cada ensaio.

Tabela 01. Valores experimentais para volume e tempo obtidos na prática

\begin{tabular}{ccccc}
\hline Ensaio & Abertura & $\mathbf{1}$ & $\mathbf{2}$ & $\mathbf{3}$ \\
\hline \multirow{2}{*}{$\mathbf{A}$} & Volume $\left(\mathrm{m}^{3}\right)$ & 0,0150 & 0,0150 & 0,0150 \\
\cline { 2 - 5 } & Tempo $(\mathrm{s})$ & 101,50 & 91,72 & 103,66 \\
\hline \multirow{2}{*}{ B } & Volume $\left(\mathrm{m}^{3}\right)$ & 0,0150 & 0,0150 & 0,0150 \\
\cline { 2 - 5 } & Tempo $(\mathrm{s})$ & 40,97 & 42,59 & 39,53 \\
\hline \multirow{2}{*}{$\mathbf{C}$} & Volume $\left(\mathrm{m}^{3}\right)$ & 0,0150 & 0,0150 & 0,0150 \\
\hline \multirow{2}{*}{$\mathbf{D}$} & Tempo $(\mathrm{s})$ & 36,15 & 32,40 & 32,78 \\
\hline & Volume $\left(\mathrm{m}^{3}\right)$ & 0,0150 & 0,0150 & 0,0150 \\
\hline
\end{tabular}




\begin{tabular}{ccccc}
\hline & Tempo $(\mathrm{s})$ & 28,69 & 28,72 & 28,69 \\
\hline \multirow{2}{*}{$\mathbf{E}$} & Volume $\left(\mathrm{m}^{3}\right)$ & 0,0150 & 0,0150 & 0,0150 \\
\cline { 2 - 5 } & Tempo $(\mathrm{s})$ & 37,34 & 39,06 & 36,41 \\
\hline \multirow{2}{*}{$\mathbf{F}$} & Volume $\left(\mathrm{m}^{3}\right)$ & 0,0150 & 0,0150 & 0,0150 \\
\cline { 2 - 5 } & Tempo $(\mathrm{s})$ & 104,78 & 107,56 & 100,09 \\
\hline
\end{tabular}

Tabela 02. Valores calculados de acordo com os experimentos realizados

\begin{tabular}{|c|c|c|c|c|c|c|c|}
\hline Ensaio & $\begin{array}{c}\text { Abertura } \\
\text { Medidas } \\
\end{array}$ & 1 & 2 & 3 & Média & $\begin{array}{l}\text { Desvio } \\
\text { Padrão }\end{array}$ & $\begin{array}{l}\text { Coeficiente de } \\
\text { Variação (\%) }\end{array}$ \\
\hline \multirow{3}{*}{$\mathbf{A}$} & $\begin{array}{l}\text { Vazão Vol. } \\
\left(\mathbf{x 1 0}^{-4} \mathbf{m}^{3} \cdot \mathbf{s}^{-1}\right)\end{array}$ & 1,48 & 1,64 & 1,45 & 1,52 & 0,10 & 6,58 \\
\hline & $\begin{array}{c}\text { Vazão } \\
\text { Mássica (kg.s } \\
\text { 1) }\end{array}$ & 0,147 & 0,163 & 0,144 & 0,151 & 0,010 & 6,62 \\
\hline & $\begin{array}{c}\text { Número de } \\
\text { Reynolds } \\
\left(\mathbf{x 1 0}^{3}\right)\end{array}$ & 8,1 & 9,0 & 7,9 & 8,3 & 0,6 & 7,2 \\
\hline \multirow{3}{*}{ B } & 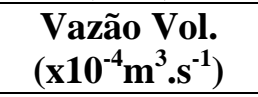 & 3,66 & 3,52 & 3,79 & 3,66 & 0,14 & 3,83 \\
\hline & $\begin{array}{c}\text { Vazão } \\
\text { Mássica (kg.s } \\
1 \text { ) }\end{array}$ & 0,365 & 0,351 & 0,378 & 0,365 & 0,014 & 3,84 \\
\hline & $\begin{array}{c}\text { Número de } \\
\text { Reynolds } \\
\left(\mathbf{x 1 0}^{3}\right)\end{array}$ & 20 & 19 & 21 & 20 & 01 & 5,0 \\
\hline \multirow{3}{*}{ C } & $\begin{array}{l}\text { Vazão Vol. } \\
\left(\mathbf{x 1 0}^{-4} \mathbf{m}^{3} \cdot \mathrm{s}^{-1}\right)\end{array}$ & 4,15 & 4,63 & 4,58 & 4,45 & 0,26 & 5,84 \\
\hline & $\begin{array}{c}\text { Vazão } \\
\text { Mássica (kg.s } \\
\text { 1) }\end{array}$ & 0,414 & 0,462 & 0,456 & 0,444 & 0,026 & 5,86 \\
\hline & $\begin{array}{l}\text { Número de } \\
\text { Reynolds } \\
\left(\mathbf{x 1 0}^{3}\right)\end{array}$ & 23 & 25 & 25 & 24 & 01 & 4,2 \\
\hline \multirow{3}{*}{ D } & 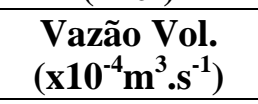 & 5,23 & 5,22 & 5,23 & 5,23 & 0,01 & 0,19 \\
\hline & $\begin{array}{c}\text { Vazão } \\
\text { Mássica (kg.s } \\
\text { 1) } \\
\end{array}$ & 0,521 & 0,521 & 0,521 & 0,521 & 0,000 & 0,00 \\
\hline & $\begin{array}{c}\text { Número de } \\
\text { Reynolds } \\
\left(\mathbf{x 1 0}^{3}\right) \\
\end{array}$ & 29 & 29 & 29 & 29 & 00 & 0,0 \\
\hline \multirow{3}{*}{$\mathbf{E}$} & $\begin{array}{l}\text { Vazão Vol. } \\
\left(\mathbf{x 1 0}^{-4} \mathrm{~m}^{3} \cdot \mathrm{s}^{-1}\right)\end{array}$ & 4,02 & 3,84 & 4,12 & 3,99 & 0,14 & 3,51 \\
\hline & $\begin{array}{c}\text { Vazão } \\
\text { Mássica (kg.s } \\
\text { 1) }\end{array}$ & 0,400 & 0,383 & 0,411 & 0,398 & 0,014 & 3,52 \\
\hline & $\begin{array}{c}\text { Número de } \\
\text { Reynolds } \\
\left(\mathbf{x 1 0}^{3}\right)\end{array}$ & 23 & 22 & 23 & 23 & 01 & 4,3 \\
\hline \multirow[b]{2}{*}{$\mathbf{F}$} & $\begin{array}{l}\text { Vazão Vol. } \\
\left(\mathbf{x 1 0}^{-4} \mathrm{~m}^{3} \cdot \mathrm{s}^{-1}\right)\end{array}$ & 1,43 & 1,39 & 1,50 & 1,44 & 0,06 & 4,17 \\
\hline & $\begin{array}{c}\text { Vazão } \\
\text { Mássica (kg.s } \\
\text { 1) }\end{array}$ & 0,143 & 0,139 & 0,149 & 0,144 & 0,005 & 3,47 \\
\hline
\end{tabular}




\section{Número de \\ Reynolds $\left.(\mathbf{x 1 0})^{3}\right)$ \\ $\begin{array}{lllll}8,0 & 7,8 & 8,4 & 8,1 & 0,3\end{array}$ \\ 3,7}

Desta forma, foram calculadas as propagações de incertezas como previamente estabelecido, encontrando, assim, um valor percentual de, aproximadamente, 17\% para as medidas estabelecidas, em função das incertezas dos instrumentos utilizados. De acordo com os resultados encontrados no software, pode-se afirmar que tanto a régua, quanto o cronômetro apresentam boa calibração para as faixas de valores medidos, sendo que a parcela que representa quase $100 \%$ da incerteza do resultado é a incerteza do indicador de nível do tanque volumétrico, afinal possui uma incerteza grande com relação à faixa das outras incertezas.

Com relação aos erros experimentais, observa-se que o experimento demonstrou certa confiabilidade nos resultados, tendo em vista a variação dos resultados. Essa confiabilidade, ou variação é medida pelo coeficiente de variação, que, exceto em alguns casos, apresentou variação menor que 5\%, mostrando uma confiabilidade dos resultados de mais de $95 \%$.

Tendo em vista o aprimoramento do experimento, analisou-se algumas das possíveis causas dessa variação dos resultados. Os erros que são mais facilmente identificados são relacionados ao manuseio de diferentes instrumentos por diferentes pessoas simultaneamente. Bem como um erro associado aoindicador de nível do tanque volumétrico que apresenta, como dito anteriormente, uma incerteza muito grande devido à sua medida ser analógica e apresentar grande divisão entre as escalas, o que necessita de grande perícia do indivíduo realizando a medição do volume.

Cabe ressaltar que a bomba foi operada dentro do seu limite de capacidade, uma vez que as vazões encontradas giraram em torno de 0,0001 a $0,0005 \mathrm{~m}^{3} \mathrm{~s}^{-1,}$ e sua vazão máxima suportada é de $60 \mathrm{~L} \mathrm{~min}^{-1}$, que equivale a $0,0010 \mathrm{~m}^{3} \mathrm{~s}^{-1}$. Com isso, garante-se ainda mais a validade do experimento proposto.

Sendo assim obtidos os resultados encontrados na tabela, pôde-se analisar algumas características dos ensaios realizados. Como o tipo de escoamento que para todos os 6 ensaios, como definido anteriormente, é caracterizado como turbulento, afinal todos os Re são maiores que 8.000 .

\section{CONCLUSÃO}

Os instrumentos abordados e utilizados em práticas relacionadas à disciplina de Fenômenos de Transporte - Mecânica dos Fluidos são cruciais para a compreensão e visualização da aplicabilidade da disciplina. Tal necessidade é perceptível ao compreender que, na disciplina citada, é essencial o 
entendimento do funcionamento das linhas de transporte dos fluidos.

Sendo assim, o objetivo de realizar uma revisão teórica acerca do assunto, a fim de apresentar como base de futuros estudos da disciplina, foi alcançadoao analisar esses equipamentos, descrevê-los e discursar sobre eles, conforme exposto na Revisão Teórica.

Esperava-se do procedimento experimental a aplicação de conceitos de mecânica dos fluidos, o que foi obtido com sucessoao se utilizar uma bomba adequada às vazões medidas, possibilitando caracterizar os escoamentos a partir dos números de Reynolds.

Para tanto, percebe-se a efetividade do método descrito para a compreensão dos conceitos desejados. Em suma, oexperimento, da forma como apresentado, amplia os conhecimentos dos estudantes de uma forma satisfatória.

\section{REFERÊNCIAS}

ACEPIL. Disponível em: $<$ http://www.acepil.com.br/artigos/valvulas-3vias> Data de acesso: 21 de abril de 2016.

\section{AMORIM, T. O. Curso de Tecnologia em} Construção Naval. Rio de Janeiro, 2010. Disponível em: <http://www.ebah.com.br/content/ABAAABg ZsAK/valvulas>. Acessado em: 22 de abril de 2016.

ANDRADE, L. C. M.; HORTA, M. D. M. Programa de Certificação de Pessoal de Manutenção, Mecânica, Tubulação e Conexões. Disponível em: <http://www.abraman.org.br/arquivos/75/75.p df $>$. Acessado em: 21 de abril de 2016.

\section{ANTONIO CLÉLIO RIBEIRO. Curso De} Tubulações Industriais. Faculdade De Engenharia Química De Lorena. Disponível em:

<http://ftp.demec.ufpr.br/disciplinas/TM141/a ula01.pdf $>$. Data de acesso: 22 de abril de 2016.

\section{BOJORGE, N. Aula 06: Sistema de} Medição de Nível. Universidade Federal Fluminense, 2014. Disponível em: $<$ http://www.professores.uff.br/controledepro cessos-eq/images/stories/Aula06_InstrumentNIVEL_1sem2014.pdf>. Acessado em: 22 de abril de 2016.

Bombas: guia básico / Eletrobrás [et al.]. Brasília: IEL/NC, 2009. Disponível em: $<$ http://arquivos.portaldaindustria.com.br/app/ conteudo_18/2014/04/22/6281/Bombas.pdf>. Data de acesso: 21 de abril de 2016.

\section{BRASIL, A. N. Hidráulica Básica e} Máquinas de Fluxo. Disponível em: $<$ http://livrozilla.com/doc/579587/capitulo-ii-teoria-geral-das-maquinas-de-fluxo> Data de acesso: 22 de abril de 2016.

CONSTRUFÁCIL RJ. Disponível em: $<$ http://construfacilrj.com.br/tubos-econexoes-instalacoes-hidraulicas/> . Data de acesso: 22 de abril de 2016.

\section{CREMASCO, M. A. Operações Unitárias} em Sistemas Particulados e Fluidomecânicos. 2 ${ }^{a}$ Edição Revista. Blucher, 2011.

DANCOR. Disponível em: <http://www.dancor.com.br/produtos/centrifu gas/cam.php>. Data de acesso: 21 de abril de 2016.

ECIL. Disponível em: $<$ http://www.ecil.com.br/temperaturaindustrial/termopares/termopar-tipo-t/> . Data de acesso: 22 de abril de 2016. 
ELAN. Disponível em:

<http://www.elan.ind.br/valvulas/valvulasdiafragma.html >. Data de acesso: 21 de abril de 2016.

ELAN. Disponível em:

<http://www.elan.ind.br/produtos.html> Data de acesso: 21 de abril de 2016.

FERRAZ, F. Meios de Ligação de Tubos, Conexões de Tubulações, Válvulas

Industriais. Instituto Federal de Educação, Ciência e Tecnologia, Bahia, Campus Santo Amaro, 2009. Disponível em:

$<$ http://docente.ifb.edu.br/paulobaltazar/lib/ex e/fetch.php?media=apostila_tubulacao_ifba.p df>. Acessado em: 21 de abril de 2016.

FIGUEIREDO NETO, E.; CARDOSO, R. S. Programa de Certificação de Pessoal Instrumentação, Elementos Finais de Controle. Disponível em:

$<$ http://www.sr.ifes.edu.br/ rafael/ii2/apostila s/valvulas/Apostila\%20Valvulas.pdf $>$.

Acessado em: 21 de abril de 2016.

\section{FUNDAÇÃO DE ENSINO E PESQUISA DE} ITAJUBÁ. Notas de Aula: Fenômenos de

Transporte. Disponível em:

<http://www.machadosobrinho.com.br/arquiv os/material_dos_professores/APX_EPSFENT /Material_didatico/01ApostiladeFenmenodeT ransportes.pdf $>$. Acessado em: 03 de julho de 2016.

GENOVALVULAS. Disponível em: $<$ http://www.genovalvulas.com.br/materiaishidraulicos/produto/valvula-redutora/valvularedutora-eurobrass-3-4.htm: Data de acesso: 21 de abril de 2016.

GERMEK. Disponível em:

<http://incendio.germek.ind.br/produto/mano metro-100mm>. Data de acesso: 22 de abril de 2016.

GOMES, M. H. R. Apostila de Mecânica dos Fluidos. Disponível em: $<$ http://www.ufjf.br/engsanitariaeambiental/fil es/2012/09/Apostila-de-Mec\%C3\%A2nicados-Fluidos.pdf $>$. Data de acesso: 03 de julho de 2016.
KLOECKNERMETALS. Manual Técnico De Tubos De Aço Carbono Com Costura. 2009. Disponível em:

<http://www.kloecknermetals.com.br/pdf/4.p df> . Data de acesso: 22/04/2016.

LEROY MERLIN. Disponível em:

$<$ http://www.leroymerlin.com.br/dicas/conhec a-os-diferentes-tipos-de-bombas-dagua> .

Data de acesso: 21 de abril de 2016.

MARINHO, C. S.; ABUD, A. K. Medição de

Temperatura. Disponível em:

$<$ http://www.ebah.com.br/content/ABAAAAv MAAE/medidores-temperatura $>$. Acessado em: 03 de julho de 2016.

MERITO COMERCIAL. Disponível em: $<$ http://www.meritocomercial.com.br/bombainjetora-ferrari-bi-10-1-cv/p201400250001>.

Data de acesso: 21 de abril de 2016.

MOURA JUNIOR, C. F.; MELO, K. F. M. S. Bombas simples, em série e em paralelo. Disponível em: $<$ https://www.passeidireto.com/arquivo/5196 350/bombas-simplesem-serie-e-em-paralelo>. Data de acesso: 03 de julho de 2016.

NETZSCH. Disponível em: <http://www.netzsch.com.br/website/pt_br/pr odutos.info.php? show=127>. Data de acesso: 21 de abril de 2016.

ORTEGA, E. Aula 8: Acessórios. Aulas 14 e 15: Bombas. Disponível em:

<www.unicamp.br/fea/ortega/aulas>. Data de acesso: 22 de abril de 2016.

PARKER. Disponível em: <http://www.parker.com/literature/Brazil/230 0_11.pdf $>$. Data de acesso: 22 de abril de 2016.

PEDREIRAO. Disponível em: $<$ http://pedreirao.com.br/instalacoeshidraulicas/tipos-de-tubos-pvc-cpvc-ppr-pexpvc-esgoto/>. Data de acesso: 22 de abril de 2016. 
PERRY, R. H.; GREEN, D. W. Perry's

Chemical Engineer's Handbook,

$7^{\text {th }}$ edition.Editora McGraw-Hill, 1997.

SMITH, J. M.; VAN NESS, H. C.; ABBOTT,

M. M. Introdução à termodinâmica da

engenharia química. 7. Ed. Rio de Janeiro:

LTC, 2007.

TELLES, P. C. S. Tubulações Industriais:

Materiais, Projeto, Montagem. 10. Ed.

Reimpressão. Rio de Janeiro: LTC, 2005.

THEBE BOMBAS HIDRÁULICAS LTDA.

Manual de instalação, Operação e

manutenção. Disponível em:

<http://www.pipers.com.br/Catalogo/painel/d

ocumento/MANUAL\%20DE\%

20INSTALA $\%$ C7\%C3O $\% 20 O P E R A \% C 7 \%$

C3O\%20E\%20MANUTEN\%C7\%C3O\%20(c

ompacto).pdf> Data de acesso: 21 de abril de

2016.

TLV. Disponível em:

<http://www.tlv.com/global/BR/steam-

theory/types-of-valves.html>. Data de acesso:

21 de abril de 2016.

TLV. Disponível em:

<http://www.tlv.com/global/BR/steam-

theory/what-is-a-steam-trap.html >. Data de

acesso: 22 de abril de 2016.

WEIR. Disponível em:

$<$ https://www.global.weir/products/product-

catalogue/>. Data de acesso: 21/04/2016.

WHITE, F. M. Mecânica dos Fluidos. 6. Ed.

AMGH Editora Ltda. 2011

WIKA. Disponível em:

<http://www.wika.com.br/bna_pt_br.WIKA>.

Data de acesso: 22 de abril de 2016. 